\title{
The Concept of Well-being in Organisational Reality
}

\author{
DARIUSZ DANILEWICZ \\ Institute of Human Capital, Collegium of Business Administration, \\ SGH Warsaw School of Economics
}

\begin{abstract}
The well-being concept refers to other similar concepts related to people's physical, mental, emotional and intellectual well-being. In broader terms, in addition to internal dimensions, it must include external dimensions as well. In discussing the concept of wellbeing, it is worth using a holistic approach - implementing this approach in practice allows for achieving measurable organisational effects.
\end{abstract}

Keywords: human capital, personnel management, well-being, organisational health, sustainable management

JEL Classification Code: M12 


\section{Introduction}

Historically, the definitions of well-being are divided into two broad categories. The first category includes traditional neoclassical measures such as income, Gross Domestic Product, life expectancy and poverty indicators. The second covers subjective or psychological measures of a person's well-being that aim to measure what people think about their lives (Gallup-Sharecare Well-Being Index, 2009).

Figure 1. The concept of well-being compared to other similar concepts

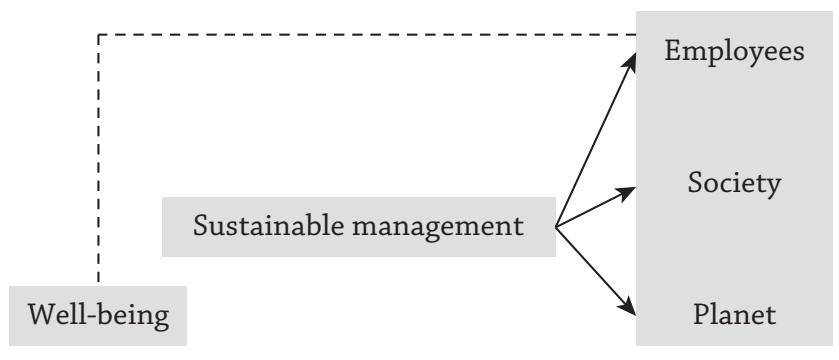

Work-life balance

Wellness

Progress

Source: own work.

A professor of psychology at the University of Illinois E. Dienner (Diener, 2005, p. 2) defines the essence of well-being as "all of the various types of evaluations, both positive and negative, that people make of their lives. It includes reflective cognitive evaluations, such as life satisfaction and work satisfaction, interest and engagement, and affective reactions to life events, such as joy and sadness." The term 'well-being', also referred to in the Polish literature as 'welfare', refers to aspects of both personal and professional life. In the narrowest sense, which the author deems incorrect, well-being focuses on physical health. Practices more and more frequently used by employers' focus on quitting smoking, losing weight, fighting stress and even prevention of certain diseases, such as spinal injuries and pains. More broadly speaking, they focus on health psychology, working with the body and appropriate nutrition. Such a perspective in the implementation of well-being programmes has many shortcomings. They are based on physical (and sometimes mental) health and well-being, forgetting other key factors. Such an approach originates from wellness 
programmes, which have been implemented in companies from Western Europe or the United States since the 1970s. The concept of wellness is expanded by the concept of work-life balance, which was born at the turn of the 1970s and 1980s in Great Britain. The main objective of the work-life balance concept was to balance work and career with the family and social life. Work-life balance is a state in which the professional and private life of individuals creates a coherent whole, serves his or her goals and expectations and is consistent with his or her principles and values. It seems that the concept of well-being is an extension of the work-life balance approach.

The author raises the research question whether the managers (or departments dealing with human capital management) of organisations operating in Poland understand the basic assumptions and components of the concept of well-being and whether they undertake its implementation.

\section{The essence of the well-being approach}

It is worthwhile to look at the topic of well-being holistically. This was done at the Gallup Institute, which, together with Healthways (hereafter referred to as Sharecare), conducted extensive research (Gallup-Sharecare Well-Being Index, 2009) resulting in the development of key elements that provide employees with a sense of satisfaction and fulfilment in their daily lives, including at work. These five key factors that determine the essence of well-being are (Employees Need High Well-being for High Performance):

- Purpose: a sense of purpose and satisfaction with functioning in private and professional life, being motivated to achieve goals;

- Social: supportive relationships (including emotional) and relations as well as a friendly atmosphere;

- Financial: dealing with the economic aspects of life, a sense of financial security;

- Community: a safe and friendly living environment, being proud of the community to which you belong and, in an organisational context, being part of a team;

- Physical: good health and energy resources for daily activities.

The assumptions of well-being are part of the positive psychology trend, one of whose fathers is M. Seligman. In his publications (Seligman, 2002; Seligman, 2011), he distinguished five elements of human well-being that directly translate into personal and professional life. This model (called PERMA) consists of the following elements: - $\quad \mathbf{P}$ - Positive emotions, e.g. joy, recognition, comfort, inspiration, hope or curiosity. The ability to concentrate on positive emotions is more than just a smile. This positive view of life can help in relationships and work and inspire to be more creative and take on more challenges. Positivity, i.e. feeling positive emotions, 
is also reflected in the atmosphere at work and, for many employees, a good atmosphere at work is one of the key elements of the sense of well-being;

- E-Engagement, also related to flow. This concept was created by M. Csíkszentmihályi, who considered the flow to be a state between satisfaction and euphoria, caused by a complete surrender to an activity. This state is achieved when an individual is competent enough to cope with the task and the challenge motivates him or her to act. The person commits his/her skills to the task, surrenders to the activity and derives satisfaction from it. In this state, the employee feels strong and effective;

- $\quad \mathbf{R}$ - Relationships, i.e. being among people, cooperation, supporting relations. Social relations and relationships are one of the most important aspects of human life. That is why a supportive workplace environment, with people who are kind to each other and where you can feel support and acceptance, is so important;

- M-Meaning, or sense of meaning - knowledge of a person's purpose and meaning gives them a reason to live and makes them aware of the sense of existence. A sense of meaning at work is the awareness of how important and necessary work is, what it can give to the employee and others, why he or she does it and how important it is in his or her life;

- A - Accomplishment/Achievement, i.e. achievements and appreciation of what you do. Having goals and ambitions in life helps an individual to achieve things that can provide them with a sense of happiness and fulfilment. Sometimes, just trying to achieve your goals can already give you a sense of satisfaction.

The use of the PERMA model by leaders positively influences employee engagement, motivation at work, identification with the organisation and loyalty, and thus supports the organisation in achieving its business objectives.

The well-being approach is becoming the most valuable and effective element in the management of modern organisations. It is worth noting that the proper implementation of well-being projects may determine the success of employees, the growth of the organisation and the development of societies. The key seems to be the right approach to implementing the assumptions of well-being in organisations so that they become an integral part of them, and not only an action having the character of employer branding (internal or external).

M. Swarbrick and J. Yudof presented the key dimensions of well-being (Swarbrick \& Yudof, 2015). Four of them are of internal nature (i.e. relating to the person concerned):

- physical well-being - energy, fitness, vitality, strength;

- spiritual well-being - sense of meaning in life, life values, spirituality;

- mental (emotional) well-being - awareness of emotions and ability to manage them, coping with stress;

- intellectual well-being - open-mindedness, willingness to explore, learn. 
The next four cover the external dimension:

- relations - building supportive relations with other people, contacts, affiliation;

- finance - a sense of financial security, financial management, attitude towards money;

- career and development - coherence between what an individual does and his or her talents, a sense of creating value for oneself and others, opportunities for development, social value;

- natural environment - the environment in which the individual lives, mutual influence of the individual and the environment.

Figure 2. Dimensions of well-being according to M. Swarbrick and J. Yudof

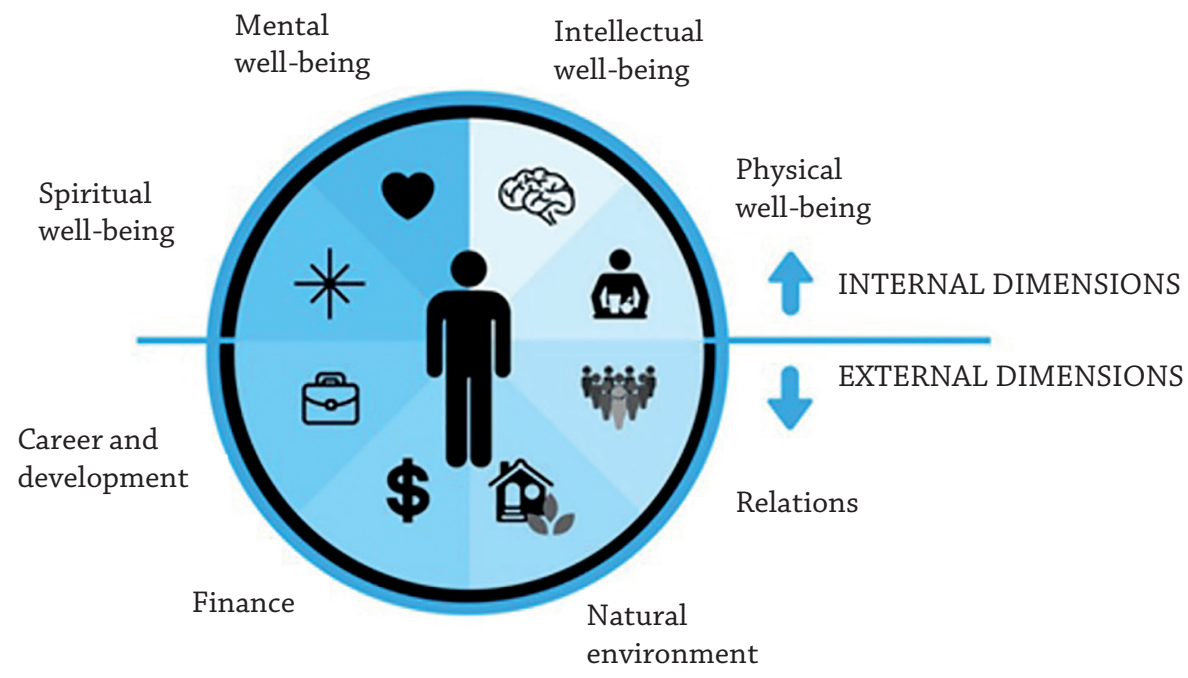

Source: own work based on M. Swarbrick \& J. Yudof (2015).

The elements presented in the above model can be shaped to a large extent by appropriate organisation management and human capital management. From here we are not far from the concept of sustainable management (Sustainable Management).

\section{Well-being and healthy organisation}

The concept of well-being refers, on the one hand, to the personal and professional life of the individual and, on the other hand, to the functioning of the organisation. The sense of well-being has a strong impact (which is shown in the findings of the 
Gallup Institute research, as mentioned earlier) on business effects. Against this background, the concept of organisational health has been developed in recent years.

However, there is no consensus on what health actually means for organisations. Some scientists and managers identify organisational health with culture, others with effectiveness or efficiency measured by concrete financial results, and others with employee engagement. Some researchers and practitioners assume that they cannot establish organisational health determinants or take steps to improve them, as this is too soft an area to be managed.

Figure 3. Organisational health elements

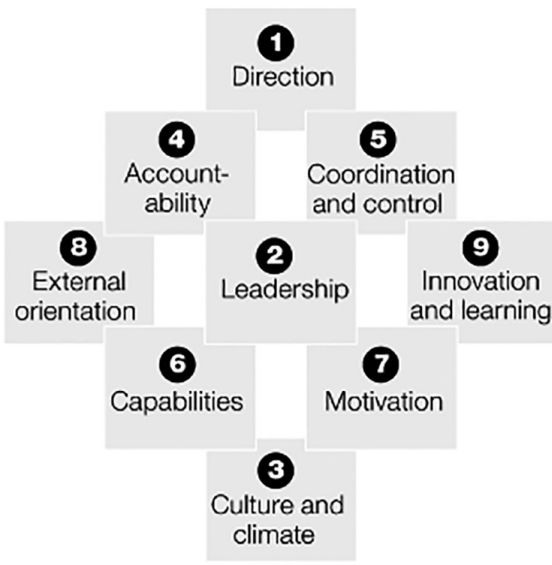

\begin{abstract}
...in three clusters
Internal alignment The organization has a compelling vision and a well-articulated strategy that is supported by its culture and climate
\end{abstract}

Quality of execution
The organization
demonstrates
excellence in executing
its strategy and
delivering its services
Capacity for renewal
The organization is
effective at understanding,
interacting with, adapting
to, and shaping its
situation and external
environment

Quality of execution excellence in executing its strategy and delivering its services

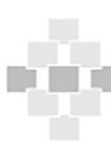

Source: S. Keller \& C. Price (2011).

In 2011, S. Keller and C. Price (Keller \& Price, 2011) presented a concept containing three key attributes of the health of an organisation: internal alignment, quality of execution and capacity for renewal, and nine elements that connect in different ways to support them (Figure 3): direction, leadership, culture and climate, accountability, coordination and control, capabilities, motivation, external orientation, innovation and learning. These nine elements are based on 37 management practices (for example, one of the practices underlying the 'direction' element is defined as "articulating a clear direction and strategy for winning and translating it into specific goals and targets"). The description of these practices makes the elements of organisational health tangible, observable and, above all, feasible. While analysing how various practices complement each other, the researchers identified four archetypes which 'healthy organisations' should follow. 


\section{Figure 4. Good practices fostering improvement of organisational health}

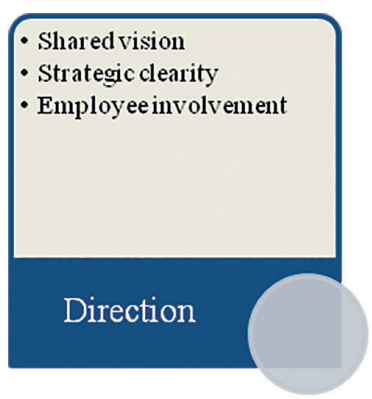

- People performance review

- Operational management

- Financial management

- Professional standards

- Risk management

Coordination

and control

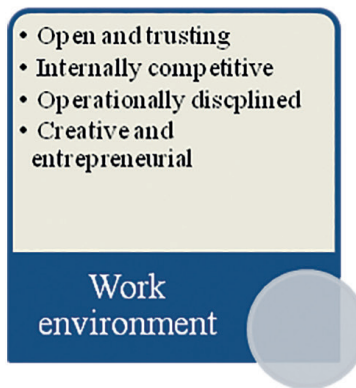

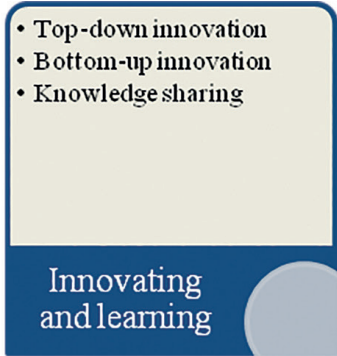

- Talent acquisitition

- Talent development

- Process-based capabilities

- Outsourced expertise

\section{Capabilities}

\section{- Role clarity}

- Perormacnce contracts

- Consequence management

- Personal ownership

Accountability

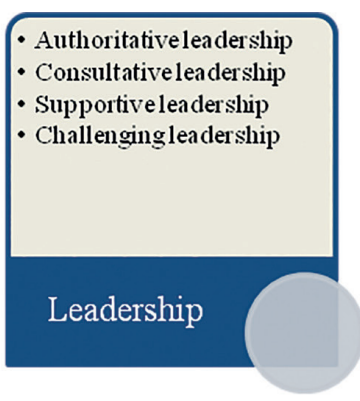

- Meaningful values

- Inspirational leaders

- Career opportunities

- Financial incentives

- Rewards and recognition

\section{Motivation}

- Capturing external ideas

- Customer focus

- Competitive insights

- Business partnership

- Government/community

relations

\section{External}

orientation

Source: own work based on Organizational Health Index.

Each archetype is characterised by a particular combination of practices that promote organisational health. These archetypes are as follows:

- in the leadership-driven archetype, leaders are the catalysts for performance, setting high expectations and supporting the organisation in achieving them;

- in the execution-edge archetype, discipline, sound execution, and continuous improvement are the foundation for great performance;

- in the market-focus archetype, shaping market trends and building a portfolio of strong and innovative brands keep the business ahead of the pack;

- in the knowledge-core archetype, talent and knowledge are the organisation's most important assets, and it develops and deploys them effectively. 
McKinsey has defined organisational health (Organizational Health Index) as follows: an organisation's ability to adapt and achieve its strategic goals based on the aforementioned management practices in Figure 4 to determine the Organisational Health Index (OHI). Organisational health is more than just the culture or employee engagement. It is the ability of an organisation to align with the shared vision, to execute this vision effectively and to renew itself through innovation and creative thinking. Research conducted over nearly a decade focusing on the monitoring of organisational health and implementing appropriate measures to improve it has shown that the implementation of the right combination of good practices has contributed significantly to the improvement of employee well-being and organisational well-being.

\section{Principles for implementing well-being programmes}

Caring for the well-being may form part of comprehensive actions in the field of corporate social responsibility. It can be used to build relationships with many stakeholder groups. Thanks to well-being programmes based on bilateral communication, the employer can create the type of relations with the company's stakeholders that build its brand. Positive relations with employees support the company's reputation as a good employer. As a result, they provide image benefits often supported by external recognition and awards. However, the foundation of success is the real value in the form of a unique Employee Value Proposition (EVP), which is manifested in the overall experience of an employee of a given company and that can tie an employee to the company in the long term. It is so precisely because of the need for consistency between declarations and the real company's everyday life that well-being actions of a strategic nature are the most effective. Only then, instead of being an ornament, do they constitute one of the elements of an organisation's identity (Zych, Well-being...).

When making a decision on the implementation of well-being programmes and policies in the organisation, it is worthwhile to involve many groups of employees in the adaptation of activities in this area, however, the most important role is played by managers. Firstly, they must be aware that the construction of a wellbeing culture is based on several of the basic pillars mentioned above and that each of them is important. Secondly, the following principles will be relevant to their operation (Zych, O co chodzi...):

- a multi-level, sustainable well-being programme should be introduced; it is not enough to limit oneself to randomly undertaking pro-health actions and benefit programmes; 
- coherent communication actions should be undertaken, which will contribute to the change of the organisational culture; communicate what well-being is and why it is important for employees;

- set an example with your own activities by participating in the organisation's programmes (e.g. quitting smoking, eating healthy food, volunteering, etc.);

- the use of all facilities should be encouraged in order to be particularly attentive to understanding how important the well-being of the company's employees is to the company;

- measure and monitor the effects of actions taken to maintain programmes that work and to stop those that do not affect the well-being of employees.

American work psychologist P. Warr identified twelve factors that have a significant impact on the well-being of employees. On this basis, he created the so-called Warr's vitamin model (Obuchowska, Nowoczesne narzędzia...). The researcher compared the mentioned twelve features to vitamins, which, depending on the level of occurrence in the 'organisation's organism', have a positive or negative impact on its functioning.

Features belonging to group I should not exceed the limit value, because at a higher level they are already harmful (the same as fat-soluble vitamins are for the human body). They include personal control, use of employee's abilities and skills, requirements and goals, range of different tasks, transparency of expectations and evaluation, level of social contacts.

The values of features belonging to group II should be as high as possible (similarly to how water-soluble vitamins work) and include physical security, significant social position, supporting supervision, career prospects, fair treatment, financial remuneration.

Implementation of the well-being culture programme in the organisation brings measurable results in three areas: economic, social and image, and in the area of organisational climate (Well-being). In the first area, these benefits relate to increasing commitment and improving work efficiency, increasing innovation in the company, improving work organisation and time management, reducing errors and accidents at work, reducing absenteeism and employee turnover and greater retention, as well as improving the quality of management (leadership). In the social and image area, the well-being in the organisation helps to improve its image on the market, attract and retain talent and improve the results of the organisation's evaluation (in employee satisfaction and organisational climate surveys). On the other hand, benefits related to the organisational climate may include improvement in the personal well-being of employees, improvement in work atmosphere, increased motivation, loyalty and engagement, increased independence and responsibility, preventive healthcare. 


\section{Conclusion}

The article contains an image of the concept of well-being compared to other similar ideas. The author presents various approaches to this concept and describes the assumptions of the holistic approach to the concept of well-being, drawing attention to the role of the external dimension of well-being (not only the internal one). The author presents the optimal conditions for implementing the well-being concept and the principles of cooperation with various groups of stakeholders inside and outside the organisation. The holistic approach to the well-being concept and its proper implementation in the organisation may contribute to the increase in the organisation's value through better use of human capital.

It seems that the next elements of the analysis should be research during which it is worth focusing on the following research questions:

- how managers and HR departments perceive the concept of well-being;

- wether managers and HR departments know the factors affecting employee well-being;

- wether organisations have an employee well-being strategy and if they implement it in practice;

- whether managers and HR departments try to measure the effectiveness of applying the well-being concept.

\section{References}

Diener, E. (2005). Guidelines for national indicators of subjective well-being and ill-being. Social Indicators, Network News, 84, 4-6.

Employees Need High Well-being for High Performance. Retrieved from: https://www.gallup.com/workplace/215924/evolve-programs.aspx (7.10.2019).

Gallup-Sharecare Well-Being ${ }^{\mathrm{TM}}$ Index: Methodology Report for Indexes. Retrieved from: https://news.gallup.com/poll/195539/gallup-healthways-index-methodologyreport-indexes.aspx (7.10.2019).

Keller, S., \& Price, C. (2011). 3 Attributes to Diagnose Organizational Health (Performance Isn't One of Them). Retrieved from: https://chiefexecutive.net/your-companys-health-performance-is-not-enough/ (6.11.2019).

Obuchowska, K. Nowoczesne narzędzia badania well-being pracowników. Retrieved from: http://www.hrtrendy.pl/2014/04/23/nowoczesne-narzedzia-badania-well-beingpracownikow-cz-1/ (21.10.2019).

Organizational Health Index. Retrieved from: https://www.mckinsey.com/solutions/ orgsolutions/overview/organizational-health-index (11.10.2019). 
Seligman, M.E.P. (2011). Flourish: A Visionary New Understanding of Happiness and Well-Being. New York: Atria Books - Simon \&schuster.

Seligman, M.E.P. (2002). Authentic Happiness: Using the New Positive Psychology to Realize Your Potential for Lasting Fulfillment. New York: Atria Books - Simon \&schuster.

Sustainable Management. Retrieved from: https://sustain.wisconsin.edu/sustainability/ sustainable-management/ (11.10.2019).

Swarbrick, M., \& Yudof, J. (2015). Wellness in 8 Dimensions. Freehold: Collaborative Support Programs of NJ, Inc.

Well-being - pozytywny potencjat organizacji. Retrieved from: http://wellbeingworganizacji.pl/wellbeing/ (6.11.2019).

Zych, B. O co chodzi z zadbaniem o well-being pracowników. Retrieved from: https:// hrstandard.pl/2014/07/31/o-co-chodzi-z-zadbaniem-o-well-being-pracownikow/ (21.10.2019).

Zych, B. Well-being w firmie - warto podejść do niego strategicznie. Retrieved from: https:// hrstandard.pl/2017/09/26/well-being-w-firmie-dlaczego-warto-podejsc-do-niegostrategicznie/ (21.10.2019).

\section{Dariusz Danilewicz}

Assistant Professor at the Institute of Human Capital, SGH Warsaw School of Economics. His research topics are related to management strategy in business and public administration, human capital management, tourism management, leadership, labourmarketpolicies, education system, development of entrepreneurial attitudes and career counselling.

e-mail address: dariusz.danilewicz@sgh.waw.pl

ORCID: 0000-0001-5338-4763 